\title{
Consumo de frutos por três espécies de Picidae em área de Floresta Ombrófila Mista de Santa Catarina
}

\author{
Nicholas Kaminski \\ Universidade Federal do Paraná \\ Rua Alberto Erthal, 446, São Lourenço, Curitiba, CEP 82.210-200, PR \\ Brasil nicholas.kaminski@yahoo.com.br
}

Submetido em 21/03/2012

Aceito para publicação em 11/04/2013

\section{Resumo}

Embora pica-paus sejam basicamente insetívoros, para algumas espécies é reconhecido o consumo de vários tipos de matéria vegetal, como frutos, sementes e néctar. Esta nota traz informações sobre eventos de frugivoria observados esporadicamente, envolvendo três espécies de Picidae (Piculus aurulentus, Veniliornis spilogaster e Dryocopus lineatus), em área de Floresta Ombrófila Mista no município de Rio Negrinho, Santa Catarina. O comportamento utilizado pelas aves para remoção dos frutos foi o mesmo para as três espécies. As quantidades consumidas variaram de acordo com o vegetal e com a espécie de ave.

Palavras-chave: Floresta Ombrófila Mista; Frugivoria; Picidae

\section{Abstract}

Fruit consumption by three Picidae species in an area of Mixed Ombrophilous Forest in Santa Catarina. Although woodpeckers are primarily insectivores, for some species one recognizes the consumption of many types of plant matter, such as fruits, seeds, and nectar. This note provides information on frugivory events sporadically observed, involving three Picidae species (Piculus aurulentus, Veniliornis spilogaster, and Dryocopus lineatus), in an area of Mixed Ombrophilous Forest in the town of Rio Negrinho, Santa Catarina, Brazil. The behavior used by birds for fruit removal was the same for the three species. The amounts consumed varied according to the plant and the bird species.

Key words: Frugivory; Mixed Ombrophilous Forest; Picidae

A família Picidae é representada por aves quase cosmopolitas, sendo o neotrópico a região mais rica em espécies (SICK, 1997; WINKLER; CHRISTIE, 2002). Embora pica-paus se alimentem principalmente de artrópodes, é reconhecido o consumo de vários tipos de matéria vegetal, como frutos, sementes e néctar (SCHUBART et al., 1965;. SICK, 1997; WINKLER; CHRISTIE, 2002; ROCCA et al., 2006).
Eventos de frugivoria são relativamente comuns entre os Picidae neotropicais, especialmente nos gêneros Melanerpes e Celeus (SCHUBART et al., 1965;. SKUTCH, 1980; KATTAN, 1988; MARCONDESMACHADO; ARGEL DE OLIVEIRA, 1988; ARGEL DE OLIVEIRA, 1992; POULIN et al., 1994; PIZO, 1997). Além destes, há ainda citações de outros gêneros fazendo uso de frutos na sua dieta 
(SICK, 1997; MIKICH, 2001; TUBELIS, 2007; VASCONCELLOS et al., 2008).

A presente nota traz informações sobre eventos de frugivoria envolvendo três espécies de Picidae (Piculus aurulentus, Veniliornis spilogaster e Dryocopus lineatus) em área de Floresta Ombrófila Mista no município de Rio Negrinho, Santa Catarina. As observações diretas dos eventos foram realizadas esporadicamente com auxílio de binóculos $8 \times 42$, durante inventário ornitológico nos anos de 2009 e 2010.

Neste período foram realizados registros de consumo quantidades consideráveis de diásporos de Miconia cinerascens, Myrsine coriacea e M. gardneriana por Piculus aurulentus. Os frutos eram apanhados e engolidos inteiros, um após o outro utilizando a técnica de "apanhar empoleirado" (perch-gleaning), segundo Fitzpatrick (1980). As quantidades consumidas variaram de acordo com o vegetal (18 diásporos no caso de $M$. coriacea; 12 em M. gardneriana e sete em M. cinerascens) e foram visualizadas apenas em uma oportunidade para cada vegetal. Vasconcellos et al. (2008) relatam que $P$. aurulentus é um dispersor de Myrsine umbellata em área de Floresta com Araucária de Minas Gerais. Jesus e Monteiro-Filho (2007) descrevem essa espécie como um importante dispersor de M. coriacea em Floresta com Araucária no estado do Paraná.

Veniliornis spilogaster foi observado consumindo uma maior variedade de frutos (Ilex paraguariensis, Schinus therebintifolius, Miconia cinerascens, Myrsine coriacea, Myrsine gardneriana e Zanthoxilum rhoifolium) se comparado com Piculus aurulentus. Entretanto, em todas as observações, $V$. spilogaster consumiu uma pequena quantidade de frutos (de 2 a 4 diásporos) enquanto forrageava. A técnica utilizada pela ave também foi de "apanhar empoleirado" (FITZPATRICK, 1980). Mikich (2001) já havia relatado o comportamento frugívoro de V. spilogaster na natureza, porém esse registro baseou-se no consumo de uma única espécie (Cecropia pachystachya). Assim, a presente nota amplia a diversidade de espécies vegetais utilizadas como recurso alimentar de $V$. spilogaster.

Não há registros na literatura a respeito do comportamento frugívoro de Dryocopus lineatus. Essa espécie foi observada em área de Floresta Ombrófila Mista, em uma única ocasião se alimentando de Myrsine coriacea, ingerindo grande quantidade de diásporos e forrageando ao lado das duas espécies de pica-paus anteriormente citadas, utilizando a mesma técnica de captura. Devido ao maior tamanho corpóreo em relação às demais espécies observadas, este pode ter um papel importante na dispersão de algumas espécies vegetais por consumir frutos em maior quantidade.

Todos os eventos de frugivoria de Myrsine coriacea foram registrados em maio de 2009, período esse que se caracteriza pela diminuição considerável na oferta de recursos dentro da Floresta Ombrófila Mista (LIEBSCH; MIKICH, 2009), fator decorrente das baixas médias térmicas apresentadas neste bioma. Estas observações sugerem que o consumo destes frutos complemente a dieta das aves em questão nos períodos em que há baixa disponibilidade, conforme citado por Sick (1997). O gênero Myrsine parece ser um elemento importante no fornecimento de recursos por aves dentro da Floresta com Araucária, conforme evidenciado por Jesus e MonteiroFilho (2007), Vasconcellos et al. (2008) e Basler et al. (2009). Outras espécies como Ilex paraguariensis e Miconia cinerascens também apresentaram frutificação neste mesmo período (observação pessoal), quando foram visualizados os eventos de frugivoria citados nesta nota, reforçando esta teoria.

Em virtude das espécies vegetais observadas como fonte alimentar se caracterizarem como espécies pioneiras no processo de sucessão vegetacional, ampliase a importância dos Picidae na chuva de sementes em clareiras formadas por ambientes que possuam árvores senescentes ou mortas. Estas acabam por ser preferidas pelo grupo, devido á maior oferta de invertebrados para sua alimentação (SICK, 1997), facilitando o estabelecimento do grupo de espécies vegetais pioneiras no contexto.

\section{Referências}

ARGEL DE OLIVEIRA, M. M. Comportamento alimentar de aves em Trichilia micrantha Benth. (Meliaceae) na Serra dos Carajás, PA. Boletim do Museu Paraense Emílio Goeldi, Belém, v. 8, n. 2, p. 305-313, 1992. 
BASLER, A. B.; MULLER, E. S.; PETRY, M. V. Frugivory by birds in Myrsine coriacea (Myrsinaceae) inhabiting fragments of mixed Araucaria Forest in the Aparados da Serra National Park, RS, Brazil. Revista Brasileira de Ornitologia, São Paulo, v. 17, n. 2, p. 113-120, 2009.

FITZPATRICK, J. W. Foraging behavior of neotropical Tyrant Flycatchers. The Condor, Albuquerque, v. 82, p. 43-57, 1980.

JESUS, S.; MONTEIRO-FILHO, E. L. A. Frugivoria por aves em Schinus terebinthifolius (Anacardiaceae) e Myrsine coriacea (Myrsinaceae). Revista Brasileira de Ornitologia, São Paulo, v. 15, n. 4, p. 585-591, 2007.

KATTAN, G. Food habits and social organization of acorn woodpeckers in Colombia. The Condor, Albuquerque, v. 90, p. 100-106, 1988.

LIEBSCH, D.; MIKICH, S. B. Fenologia reprodutiva de espécies vegetais da Floresta Ombrófila Mista do Paraná, Brasil. Revista Brasileira de Botânica, São Paulo, v. 32, n. 2, p. 375-391, 2009.

MARCONDES-MACHADO, L. O.; ARGEL-DE-OLIVEIRA, M. M. Comportamento alimentar de aves em Cecropia (Moraceae), em Mata Atântica, no estado de São Paulo. Revista Brasileira de Zoologia, Curitiba, v. 4, p. 331-339, 1988.

MIKICH, S. B. Consumo de frutos por quatro espécies de picapaus (Aves, Picidae) em remanescentes de Floresta Estacional Semidecidual do Sul do Brasil. Arquivos de Ciências Veterinárias e Zoologia da UNIPAR, Umuarama, v. 5, n. 2, p. 177-186, 2002.

PIZO, M. A. Seed dispersal and predation in two populations of Cabralea canjerana (Meliaceae) in the Atlantic Forest of southeastern Brazil. Journal of Tropical Ecology, Cambridge, v. 13, p. 559-578, 1997.
POULIN, B.; LEFEBVRE, G.; MCNEIL, R. Diets of land birds from northeastern Venezuela. The Condor, Albuquerque, v. 96, p. 354-367, 1994

ROCCA, M. A.; SAZIMA, M.; SAZIMA, I. Woody woodpecker enjoys soft drinks: the blond-crested woodpecker seeks nectar and pollinates canopy plants in south-eastern Brazil. Biota Neotropica, São Paulo, v. 6, n. 2, 2006. Disponível em: <http:// www.biotaneotropica.org.br/v6n2> Acesso em: 5 fev. 2012.

SCHUBART, O.; AGUIRRE, A. C.; SICK, H. Contribuição para o conhecimento da alimentação das aves brasileiras. Arquivos de Zoologia, São Paulo, v. 12, p. 95-249, 1965.

SICK, H. Ornitologia Brasileira. Rio de Janeiro: Ed. Nova Fronteira, 1997. 912 p.

SKUTCH, A. F. Arils as food of tropical American birds. The Condor, Albuquerque, v. 82, p. 31-42, 1980.

TUBELIS, D. P. Fruit consumption by Colaptes campestris (Aves, Picidae) at Emas National Park, Brazil. Biotemas, Florianópolis, v. 20, n. 4, p. 131-133, 2007.

VASCONCELOS, M. F.; D'ANGELO-NETO, S.; VIANA, F. E. C. The white-browed woodpecker Piculus aurulentus (Temminck, 1821) (Aves: Picidae) as a potential seed disperser of Myrsine umbellata Mart. (Myrsinaceae). Lundiana, Belo Horizonte, v. 9, n. 2, p. 159-160, 2008.

WINKLER, H.; CHRISTIE, D. A. Family Picidae (woodpeckers). In: DEL HOYO, J.; ELLIOTT, A.; SARGATAL, J. (Ed.). Handbook of the birds of the world. Vol. 7. Barcelona: Lynx Edicions, 2002. p. 296-555. 